\title{
Magnetic Performance of the Main Superconducting Magnets for the LHC
}

\author{
S. Sanfilippo, N. Sammut, L. Bottura, M. Di-Castro, A. Basu, J.-P. Koutchouk, E. Todesco, P. Hagen, \\ N. Catalan-Lasheras, W. Venturini-Delsolaro, C. Giloux, and R. Wolf
}

\begin{abstract}
The field strength and homogeneity of all the LHC superconducting magnets were measured as a part of the production control and qualification process that has taken place during the past four years. In addition to field measurements at room temperature performed on the integral of the production, a significant part of the magnets has been subjected to extensive magnetic measurements at cold. The measurements at cryogenic temperatures, generally performed up to excitation currents of $12 \mathrm{kA}$ corresponding to the ultimate LHC energy of 7.6 TeV, were mainly based on static and dynamic field integral and harmonic measurements. This allowed us to study in detail the DC effects from persistent current magnetization and long-term decay during constant current excitation. These effects are all expected to be of relevance for the field setting and error compensation in the LHC. This paper reports the main results obtained during these tests executed at operating conditions. The integrated field quality is discussed in terms of distribution (average and spread) of the field strength and low-order harmonics as obtained for all the main ring magnet families (dipoles, main and matching quadrupoles). The dependence of field quality on coil geometry, magnet and cable manufacturer is analyzed. A projection of the field quality expected for the critical components in the machine is presented.
\end{abstract}

Index Terms-Dipole, field quality, LHC, magnetic measurements, quadrupole, superconductivity.

\section{INTRODUCTION}

$\mathbf{T}$ HE Large Hadron Collider (LHC) at CERN is entering in its last phase of construction with the installation of the magnets in the tunnel and the commissioning of the eight octants. The machine is expected to start exploitation by mid 2008 [1]. The 1232 main bending dipoles (MB), the 392 main quadrupoles (MQ) and the 82 powered individually matching section quadrupoles (MQM, MQY) were tested for final acceptance at cryogenic temperature $(1.9 \mathrm{~K}$ or $4.55 \mathrm{~K})$ in the CERN Superconducting Magnet Test Plant [2]. The series tests started in June 2001 and were completed in February 2007. The test program for dipoles and quadrupoles included field quality measurements that were carried out at room temperature over $100 \%$ of the production and over a sample of $15-20 \%$ in operational conditions in order to steer the magnetic quality towards the beam requirements [3]. In this paper we present the field quality results related to the main LHC superconducting magnets. We focus on the integrated transfer function, on the integrated multipoles, and on three sources of field imperfection: geometric, magnetization and decay. Ramp rate effects are discussed elsewhere [4].

Manuscript received September 27, 2007.

The authors are with CERN, CH-1211 Geneva 23, Switzerland (e-mail: s.sanfilippo@cern.ch).

Color versions of one or more of the figures in this paper are available online at http://ieeexplore.ieee.org.

Digital Object Identifier 10.1109/TASC.2008.920664
All types of cross-section and cable combinations were tested at cold and the magnet number allows establishing meaningful statistical results. The shape of the field imperfections is modeled using a Gaussian distribution with average $(\mu)$ and standard deviation $(\sigma)$ of magnets measured at cold or extrapolated from room temperature based on the warm to cold correlations established for the dipoles [3] and the main quadrupoles [5].

\section{Magnet Design Features and Test Procedure}

The design of the MB, of the MQ in the short straight sections and of the matching section quadrupoles MQM and MQY is described in detail in [1], [6]-[8]. For the scope of the present paper only the main design features in view of the discussion of the test results will be recalled.

\section{A. Superconducting Cables}

Four types of Rutherford cables are used for the main superconducting magnets. The dipole and quadrupole coils consist of double layer windings, based on $15.1 \mathrm{~mm}$ wide NbTi Rutherford cables insulated using three wraps of Kapton. The MB features two layers of keystoned cables called respectively cable 01 (inner layer) and cable 02 (outer layer). The MQ inner and outer layers are made with the 02 cable. The 01 cable consists of 28 strands of $1.065 \mathrm{~mm}$ diameter, a twist pitch of $18 \mathrm{~mm}$ and has a filament size of $7 \mu \mathrm{m}$. The 02 cable contains 36 strands of $0.825 \mathrm{~mm}$ diameter, a twist pitch of $15 \mathrm{~mm}$ and a filament size of $6 \mu \mathrm{m}$. The cables 01 are produced by two firms denoted by the letters B and $\mathrm{E}$ whilst the cable 02 by five [9]. MQM and MQY coils are wound with two types of $8 \mathrm{~mm}$ wide Rutherford $\mathrm{Nb}-\mathrm{Ti}$ cables (cables 04 and 05). They have strands with respectively different $\mathrm{Cu} / \mathrm{Sc}$ ratios (1.25 and 1.75) and different diameters $(0.735 \mathrm{~mm}$ and $0.475 \mathrm{~mm}$ ), each strand containing $6 \mu \mathrm{m}$ filaments. MQM coils are wound out of cable 04 as a double layer whilst both types of cable are used for the MQY coils, (cable 04 for the two inner layers, cable 05 for the two outer layers). Cable acceptance criteria are based on control tests of magnetization, inter-strand cross contact resistance, copper to superconductor ratio, dimensional analysis and critical current. Test results and differences between manufacturers are summarized in [9].

\section{B. Coil Layout}

The population MB and MQ are made with respectively three and two generations of coil layouts that have been used to steer the production towards beam dynamic requirements [10]. The dipole base line layout (cross-section 1, Xs1) has been changed after $35 \mathrm{MB}$ through a modification in the azimuthal size of the inner layer copper wedges of 0.1 to $0.4 \mathrm{~mm}$ leaving unchanged the coil shape. This second layout (cross-section 2, Xs2) was 
TABLE I

DESIGN CHARACTERISTICS OF THE LHC MAGNETS AND NuMBER OF MAGNETS MEASURED AT COLD

\begin{tabular}{cccc}
\hline \hline $\begin{array}{c}\text { Magnet type/ } \\
\text { Operating } \\
\text { temperature [K] }\end{array}$ & $\begin{array}{c}\text { Injection } \\
\text { current [A] } \\
\text { /nominal } \\
\text { current [A] }\end{array}$ & $\begin{array}{c}\text { Magnetic } \\
\text { Field [T] or Field } \\
\text { gradient [T/m] }\end{array}$ & $\begin{array}{c}\text { Total number of } \\
\text { magnets/ } \\
\text { Number } \\
\text { measured at cold }\end{array}$ \\
\hline $\mathrm{MB} / 1.9$ & $760 / 11850$ & $0.54 / 8.33$ & $1232 / 221$ \\
$\mathrm{MQ} / 1.9$ & $760 / 11850$ & $14.5 / 223$ & $392 / 30$ \\
$\mathrm{MQM} / 1.9$ & $265 / 5390$ & $10 / 200$ & $46 / 18$ \\
$\mathrm{MQY} / 4.5$ & $176 / 3610$ & $8 / 160$ & $18 / 11$ \\
\hline \hline
\end{tabular}

used for $135 \mathrm{MB}$ and was finally modified by increasing the midplane insulation by $0.125 \mathrm{~mm}$ (cross-section 3, Xs3) to position the first allowed multipoles at the center of the band allowed by the beam dynamics. This last change was also implemented in the MQ after one quarter of the production in order to optimize the $b_{6}$ value. The MQM and MQY magnets fulfilled all requirements during qualification tests and no further design adjustments in the design were needed. The dipole production was shared between three manufacturers (firm 1, firm 2 and firm 3 ) that followed different procedures for collared coils and collars assemblies, using also two different collars suppliers and different tooling for the coil curing [11]. The MQ, MQM and MQY magnets were produced, for each magnet type, by a single manufacturer.

\section{Coil Assembly and Magnet Parameters}

The dipole and quadrupole assemblies are described in [6] and that of the matching quadrupoles in [8]. The superconducting coils are clamped in austenitic steel collars inside an iron yoke, the whole structure being contained in a shrinking cylinder. During MQ and MQY series production significant anomalies in the strength and in the allowed multipoles $\left(\mathrm{b}_{6}, \mathrm{~b}_{10}\right)$ were observed from room temperature magnetic measurements [5], [12]. This was traced back to values of the relative magnetic permeability in the collars which was in some cases out of tolerance. Permeability measurements showed typical values ranging from 1.01 to 1.02 against the specified maximum value of 1.005 . A batch of $73 \mathrm{MQ}$ and $10 \mathrm{MQY}$ is concerned. Some of them were measured at cold and a correction was therefore applied on room temperature data for the extrapolation of $b_{2}, b_{6}$ and $b_{10}$ at cold. The room temperature to cold conditions correlations are summarized in [5] for the MQ and in [12] for the MQY.

The design nominal and injection currents for the $56 \mathrm{~mm}$ coil aperture magnets (MB, MQ, MQM) and for the $70 \mathrm{~mm}$ aperture MQY are summarized in Table I. The MB are designed to ramp at $10 \mathrm{~A} / \mathrm{s}$ from $0.54 \mathrm{~T}$ (the injection field) to $8.33 \mathrm{~T}$ (the nominal field). The equivalent field gradients for the MQ are $14.5 \mathrm{~T} / \mathrm{m}$ at injection and $223 \mathrm{~T} / \mathrm{m}$ at nominal field. These values respectively correspond to injection and nominal currents of $760 \mathrm{~A}$ and $11850 \mathrm{~A}$. The design nominal currents are $3610 \mathrm{~A}$ for the MQY and 5390 A for the MQM, corresponding respectively to a field gradient of $160 \mathrm{~T} / \mathrm{m}$ and $200 \mathrm{~T} / \mathrm{m}$. Injection currents for the cold tests have been taken at 176 A for the MQY and 265 A for the MQM.

\section{Test Procedures and Measurements}

Field harmonics are first measured at room temperature at the manufacturers after the collaring and after the assembly of the
TABLE II

INTEGRATEd TRANSFER FunCtion (AVERAGE, SPREAD) AT INJECTION AND Nominal CURRENT Versus the SPREAd EXPECTED by BEAm DyNAMICS

\begin{tabular}{cccc}
\hline \hline Current level. & $\begin{array}{c}\mu \\
\text { Tm/kA }\end{array}$ & $\begin{array}{c}\sigma \\
\text { measured } \\
\text { (units) }\end{array}$ & $\begin{array}{c}\sigma \\
\text { beam dynamics } \\
\text { (units) }\end{array}$ \\
\hline Injection (760 A) & 10.116 & 9 & 10 \\
Geometric (5 kA) & 10.014 & 9 & 10 \\
Nominal (11850 A) & 10.058 & 9 & 10 \\
\hline \hline
\end{tabular}

cold mass with a rotating coil of $750 \mathrm{~mm}$ length [3] so as to detect faulty components or assembly procedures and get a picture of the geometric field errors. The cold measurements are performed in the cryo-magnets at the CERN test stations. The test sequences are described in [13] and are equivalent for all the magnet types. The MB, MQ and the MQY were cold tested in the SM18 test facility using an horizontal cryostat whilst the MQM results presented here originate from measurements performed in a vertical cryostat [14]. Measurements are carried out in operating conditions ( $1.9 \mathrm{~K}$ and $4.5 \mathrm{~K}$ as appropriate) and at several current levels including the injection and the collision plateaus. They provide the integrated field strength, the magnetic length and the field error components as a function of the current. The main sources of field imperfections, those which are of steady state in nature (geometric, saturation effect, magnetization effect) and those which are dynamic in nature (ramp rate effects, decay of magnetization) can be quantified. Tests are performed in reproducible conditions: the measurements follow a quench then same pre-cycling conditions. Field errors are given throughout in units of $10^{-4}$ relative to the main field component strength at the reference radius of $17 \mathrm{~mm}$. $\mathrm{b}_{3}$ stands for the normal sextupole term. Field quality measurements at cold were performed using rotating coil based systems [15] and cross-checked with Single Stretched Wire measurements [16] for the transfer function. This combination guarantees for the main field an uncertainty of 5 units and 1 unit for the reproducibility. Multipoles are measured with an estimated uncertainty of 0.1 units and a random error of 0.01 units.

\section{MAIN FIELD}

\section{A. MB Transfer Function Measured at Cold}

Data relative to measurements of the integrated transfer function $(\mu$ and $\sigma$ ) measured at injection, at $5 \mathrm{kA}$ (average between ramp up and ramp down) and at nominal current are presented in Table II. The spread of integrated field strength has standard deviation of 9 units at the three current levels, which is within the requirements from beam optics [10].

Table III and Table IV detail the differences in transfer function values observed between the manufacturers and the crosssections in the case of the $221 \mathrm{MB}$ measured at cold.

Differences in average between assemblers are about 7 units maximum, corresponding to a coil radius difference of $7 \mu \mathrm{m}$. The difference in the average transfer function between the cross-sections has a maximum of 9 units. The spread does not show relevant difference between manufacturers and cross-sections. It does not exceed 6 units between manufacturers.

The variation of the transfer function as a function of the current is presented in Fig. 1. Data is shifted to remove the geo- 
TABLE III

INTEGRATED TRANSFER FunCTION (AVERAGE, SPREAD) AT INJECTION AND NOMINAL CURRENTS W.R.T. THE THREE MANUFACTURERS

\begin{tabular}{ccc}
\hline manufacturer & $\begin{array}{c}\mu \text { measured } \\
(\text { Tm/kA) } \\
\text { Injection/Nominal }\end{array}$ & $\begin{array}{c}\sigma \text { measured } \\
\text { (units) } \\
\text { Injection/nominal }\end{array}$ \\
\hline Firm 1 & $10.118 / 10.060$ & $5 / 5$ \\
Firm 2 & $10.115 / 10.057$ & $5 / 5$ \\
Firm 3 & $10.120 / 10.064$ & $6 / 6$ \\
\hline \hline
\end{tabular}

TABLE IV

INTEGRATED TRANSFER FUnCTION (AVERAGE, SPREAD) AT INJECTION AND NOMINAL CURRENTS W.R.T. THE THREE CROSS-SECTIONS

\begin{tabular}{|c|c|c|}
\hline Cross-section & $\begin{array}{c}\mu \text { measured } \\
(\mathrm{Tm} / \mathrm{kA}) \\
\text { Injection/Nominal }\end{array}$ & $\begin{array}{c}\sigma \text { measured } \\
\text { (units) } \\
\text { Injection/nominal }\end{array}$ \\
\hline 1 & $10.132 / 10.065$ & $7 / 5$ \\
\hline 2 & $10.126 / 10.058$ & $5 / 5$ \\
\hline 3 & $10.122 / 10.056$ & $5 / 4$ \\
\hline
\end{tabular}
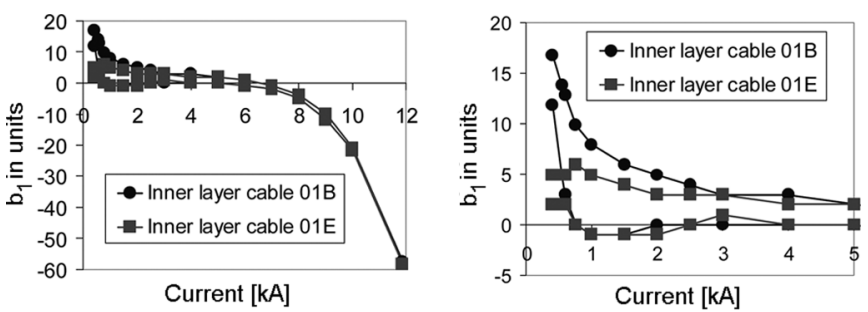

Fig. 1. Average dipole transfer functions as a function of the current (left). The hysteresis loop is emphasized in the picture in the right. The circles correspond to the MB with inner layer cable $01 \mathrm{~B}$ and the square with inner layer cable $01 \mathrm{E}$.
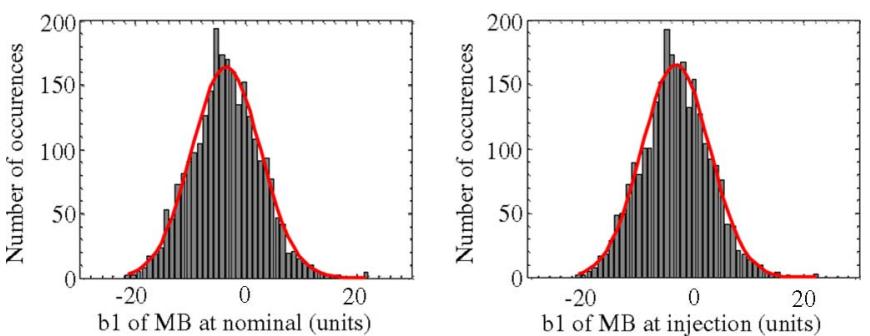

Fig. 2. Distribution of the dipole transfer function values at cold at nominal (left) and at injection field (right) expected for the LHC machine. The curve corresponds to a fit using a Gaussian distribution.

metric contribution. Distinction was done for dipoles with cable 01B and cable with 01E.

As shown in Fig. 1 the dipoles have a similar high field behavior irrespective of the cross-section, of the manufacturer and of the cable type with a saturation effect of 60 units at nominal current. At low current the hysteretic behavior caused by the persistent currents in the superconducting filament depends on the type of the inner layer cable. The width of the hysteresis loop at injection is indeed two times higher for the MB wound with cable 01B (9.4 units against 5.8 units). This effect was studied in details in [17], [18] and is related to the $10 \%$ difference of the average in magnetization among the two types of cables 01B and 01E. A small dependence of the hysteresis width on outer layer cable was found.

In Fig. 2 the distribution of the dipole transfer function expected for the machine at injection and nominal field is displayed. The data are expressed in units referred to the total expected average value at cold.
TABLE V

Transfer Function of the Field Gradient (Average, Spread) AT INJECTION, 5 kA AND NOMINAL CURRENTS vS BEAM DYNAMIC

\begin{tabular}{cccc}
\hline \hline Current level. & $\begin{array}{c}\mu \\
\text { T/kA }\end{array}$ & $\begin{array}{c}\sigma \\
\text { measured } \\
\text { (units) }\end{array}$ & $\begin{array}{c}\sigma \\
\text { beam dynamics } \\
\text { (units) }\end{array}$ \\
\hline Injection (760 A) & 58.38 & 11 & 10 \\
Geometric (5 kA) & 58.37 & 11 & 10 \\
Nominal (11850 A) & 58.29 & 11 & 10 \\
\hline
\end{tabular}

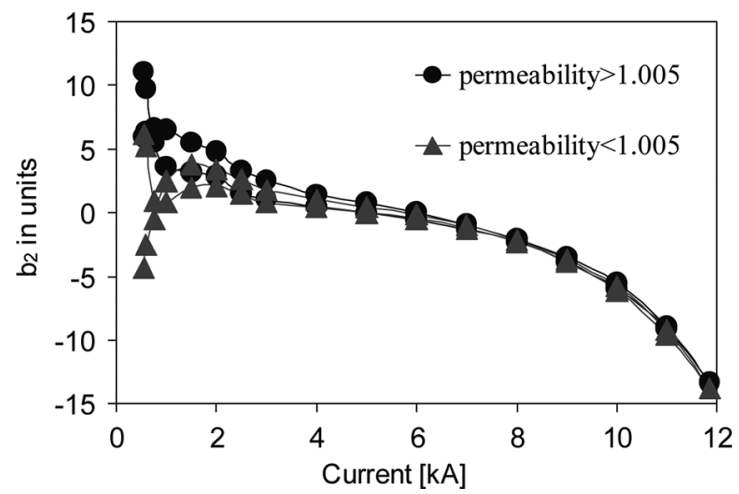

Fig. 3. MQ transfer functions measured at $1.9 \mathrm{~K}$. The circles are the average of the $7 \mathrm{MQ}$ with high value of the magnetic collar permeability $\mu \mathrm{c}$ and the triangle for the $10 \mathrm{MQ}$ with $\mu \mathrm{c}$ between 1.002 and 1.005 .

The distribution is Gaussian with a standard deviation of 6.5 units at both currents, conform to the beam dynamic requirements.

\section{B. MQ Transfer Function Measured at Cold}

Data relative to the integrated transfer function of the field gradient at $1.9 \mathrm{~K}$ measured at injection and nominal currents are given in Table V. The geometric value taken at $5000 \mathrm{~A}$ has been also added. The spread of the integrated field gradient of MQ measured at cold is 11 units, i.e. $10 \%$ more than the allowed beta beating budget.

The shape of the average transfer function with respect to the current is presented in Fig. 3 for $17 \mathrm{MQ}$, the data being shifted to remove their geometric contribution.

At high field, the iron yoke saturation affects the bending strength in a uniform way with an average reduction of 14 units. At low field (below $1 \mathrm{~T}$ ) two behaviors were identified. They are characterized by a different shape during the ramp up and ramp down and correspond either to magnets with low or high value of collar magnetic permeability. The impact of magnetic permeability $\mu \mathrm{c}$ is to increase the hysteretic width at low field (1 and 5 units for low and high magnetic permeability collar magnets at injection current).

The distribution of the transfer function of the 360 MQ expected for the machine is presented in Fig. 4 at injection (760 A) and nominal field (11850 A).

The distribution shape is affected by the presence of $90 \mathrm{MQ}$ with the first cross-section that increases by 7 units the geometric. The standard deviation is 10 units at injection and 12 units at nominal field, values close to those measured at cold in $17 \mathrm{MQ}$. The sample measured at cold was found to be representative of the magnet behavior in the machine. This out of specification spread of the field gradient will induce beta-beating that can reduce the physical aperture of the machine. A sorting 

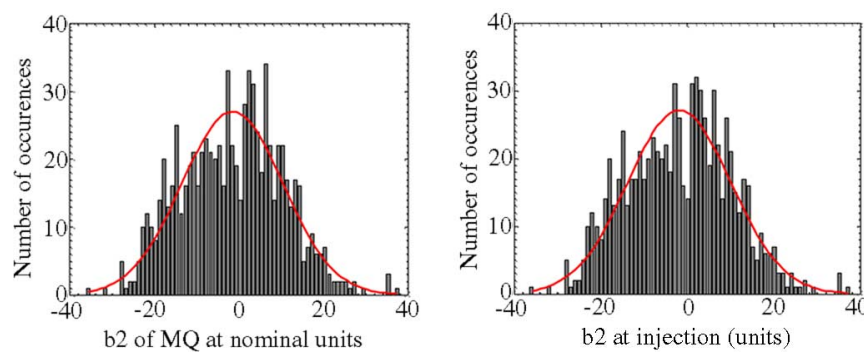

Fig. 4. Distribution of the MQ transfer function values at cold at nominal (left) and at injection field (right) expected for the LHC machine. The curve corresponds to a fit using a Gaussian distribution.
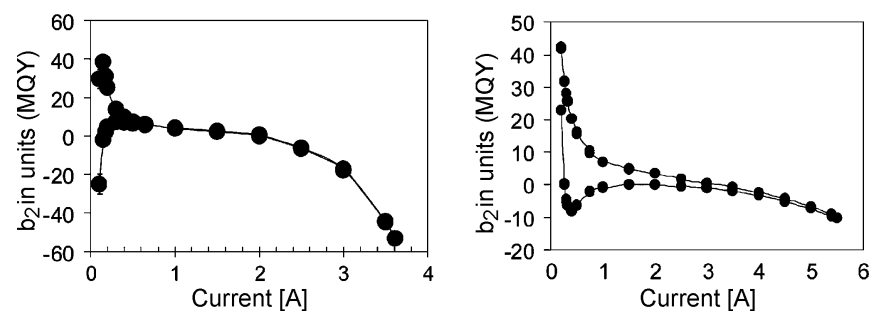

Fig. 5. Average measured transfer function (in units) of $11 \mathrm{MQY}$ (left) at 4.5 $\mathrm{K}$ and of $18 \mathrm{MQM}$ measured at $1.9 \mathrm{~K}$ (right).

strategy has been applied to reduce the integrated field gradient spread [19].

\section{Transfer Function of the $M Q M$ and $M Q Y$}

The matching quadrupoles are powered individually in the machine so we restrict our discussion to the dependence of the transfer function on the excitation current. The shape of the MQY and MQM transfer functions for currents ranging from 50 A to nominal current is displayed in Fig. 5.

For MQY a significant saturation effect is found reducing the transfer function by -58 units with respect to the geometric value taken at $2000 \mathrm{~A}$. The persistent current effects are large with an average of -27 units at a current of $176 \mathrm{~A}$. For the MQM the saturation effect reduces the transfer function by 10 units at nominal current. At injection current (265 A) the hysteretic behavior caused by the persistent current is significant with an average hysteresis loop width of 30 units.

\section{Multipoles AT 1.9 K AND $4.5 \mathrm{~K}$}

\section{A. MB Multipoles}

A plot of the spectrum of the measured field errors at injection and nominal currents is shown in Fig. 6 in the case of the 221 MB tested at cold. The solid line in these figures corresponds to the limit of the mean (systematic error plus uncertainty) and the dotted lines correspond to the $3 \sigma$ deviation around the full line derived from [10]. Distinction was done for the three successive cross-sections.

The $b_{3}$ at nominal and the $b_{5}$ at injection were largely out of specification for dipoles with the cross-section 1. The two corrective actions were effective to bring the normal sextupole in the upper part of the target range at nominal field ( +3 units) and the $b_{5}$ just above the beam dynamic targets corresponding to 1.2 units at injection. The normal 14 th pole $\left(b_{7}\right)$ is marginally above the beam dynamic targets by 0.2 units. For $b_{3}$ no differences between assemblers are found [11]. The multipoles
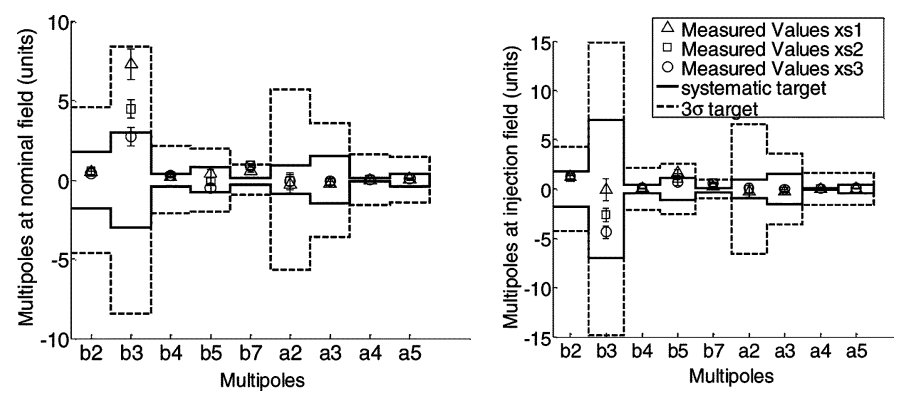

Fig. 6. Field quality at nominal field (left) and injection (right). The bars are the measured rms values. The plain and dot lines display the systematic and the 3 sigma targets. The three coil geometries are represented: cross section 1 (triangle), cross section 2 (square), cross-section 3 (circles).
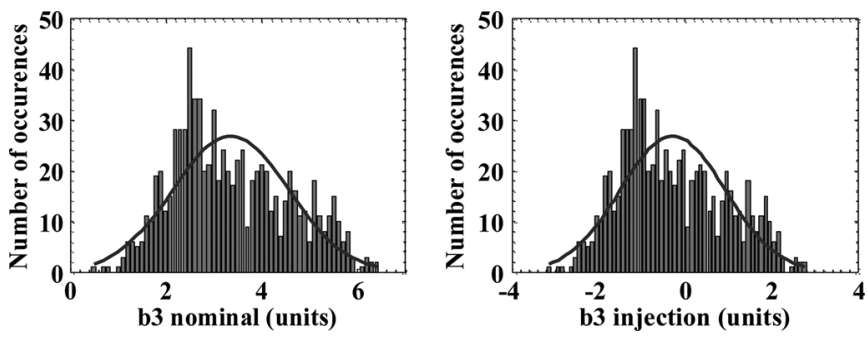

Fig. 7. Distribution of the dipole sextupole values at cold at nominal (left) and at injection field (right) expected for the LHC machine. The curve corresponds to a fit using a Gaussian distribution.

$\mathrm{b}_{5}, \mathrm{~b}_{7}$ and $\mathrm{a}_{4}$ show assembler signatures justified by coil movements of less than $100 \mu \mathrm{m}$. At injection persistent currents affect the first allowed multipoles with a contribution of respectively $-7 \pm 0.36$ units and $+1 \pm 0.1$ unit for $b_{3}$ and $b_{5}$. The measured values are conform to the expected values computed in [20] and based on strand magnetization measurements performed at the start of the production [21].

The histograms in Fig. 7 describe the distribution of the sextupole expected for the machine at injection and nominal current.

The distribution shape is not Gaussian, affected by the presence of the three cross-sections. The corrections bring the expected average for the machine to -4 units at $760 \mathrm{~A}$ and to 3 units at $11850 \mathrm{~A}$ with a spread of 1.5 units at both currents. The sextupole is in the upper part of the target range, which is optimal from the point of view of beam chromaticity. The spread is at the limit of the targets. To further reduce this random, magnets were sorted by sector [19].

\section{B. MQ Multipoles}

The average of the 30 measured multipoles is presented in Fig. 8 at injection and nominal field and compared to field constraints imposed by the beam dynamics.

Most integrated multipoles are within the allowed limits. The large spread of the $\mathrm{b}_{6}$ observed at injection and nominal fields are due to the change in cross-sections. The first series of quadrupoles show $b_{6}$ values outside the target at injection by about +1.5 units, leading a loss of dynamic aperture at injection. The corrective action taken jointly by CEA Saclay and CERN was found to be effective with a decrease of the $\mathrm{b}_{6}$ by 2 units in average measured in the MQ with the cross-section 2 (see Table VI with a statistic on $30 \mathrm{MQ}$ ). The persistent current contribution to the first allowed multipoles is 

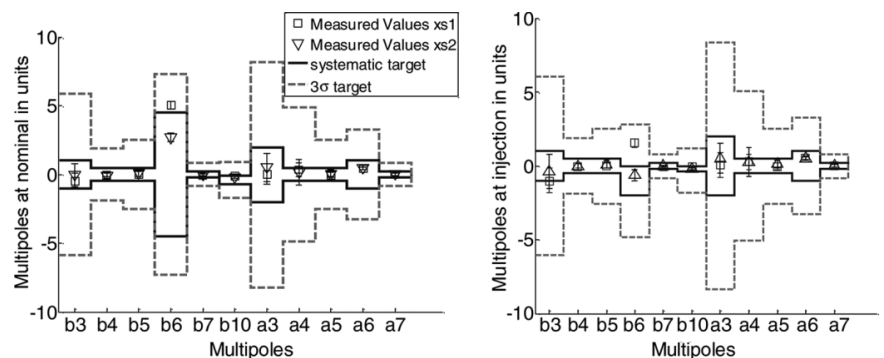

Fig. 8. Field quality at nominal field (223 T/m, left) and at injection $(14.5 \mathrm{~T} / \mathrm{m}$, right). The bars are the measured rms values. The plain and dot lines display the 1 sigma and 3 sigma targets. The MQ feature two types of cross-section, cross section 1 (square), cross section 2 (triangle).

TABLE VI

MEASUREd Multipoles $\mu$ AND STANDARD DEVIATION $\sigma$ AT $1.9 \mathrm{~K}$ AND INJECTION FIELD FOR MQ WITH THE TwO CROSS-SECTIONS

\begin{tabular}{ccccc}
\hline \hline $\begin{array}{c}\text { Multipole } \\
\text { component }\end{array}$ & $\begin{array}{c}\mu \\
\text { (units) }\end{array}$ & $\begin{array}{c}\sigma \\
\text { (units) }\end{array}$ & $\begin{array}{c}\mu \\
\text { (units) }\end{array}$ & $\begin{array}{c}\sigma \\
\text { (units) }\end{array}$ \\
\hline $\mathrm{b}_{6}$ & 1.50 & 0.50 & -0.60 & 0.40 \\
$\mathrm{~b}_{10}$ & -0.09 & 0.07 & -0.24 & 0.07 \\
\hline \hline
\end{tabular}
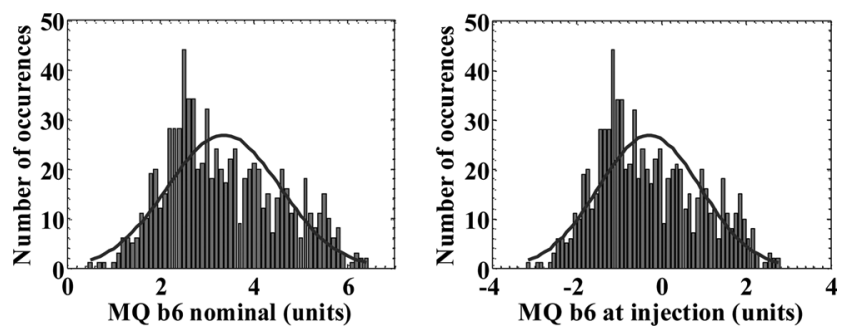

Fig. 9. Distribution of the dodecapole values extrapolated at cold at nominal (left) and at injection field (right) expected for the LHC machine. The curve corresponds to a fit using a Gaussian distribution.

for $\mathrm{b}_{6}=-3.5 \pm 0.53$ units and for $\mathrm{b}_{10}=0.03 \pm 0.07$ units and matches the expectations from cable measurements [20].

Fig. 9 displays the distribution of $b_{6}$ expected for the machine at injection and nominal field obtained using the measured values at cold and the extrapolated ones from room temperature measurements. The $\mathrm{b}_{6}$ distribution deviates from the Gaussian shape because of shift caused by the two cross-sections. The plots show an expected average of 3.5 units and -0.6 units at nominal and injection field and a random part of 1.2 units at both currents. The systematic is within the targets but the random $b_{6}$ is out of the limit due to the large impact of the cross-section change; this out of-target is however not a critical issue. The study of the skew components shows that the systematic and the random are within the targets.

\section{MQM and MQY Multipoles}

The integrated multipole components for the MQY at injection and at nominal field are summarized in Fig. 10. The solid line in these figures corresponds to the limit of the mean (systematic error) and the dotted lines correspond to the $3 \sigma$ deviation around the full line.

The average values are within the target limits apart from the $b_{6}$ that is outside the systematic boundaries at injection and nominal by 2 and 0.5 units. This discrepancy originates from an
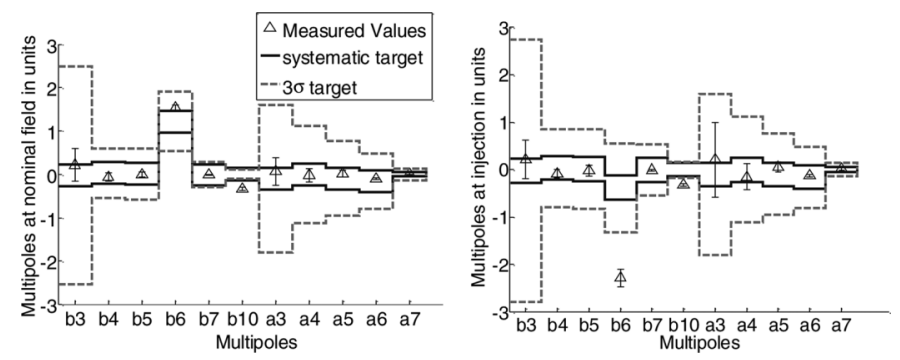

Fig. 10. Field quality at nominal (left) and injection field (right). Same legend as in Fig. 8.
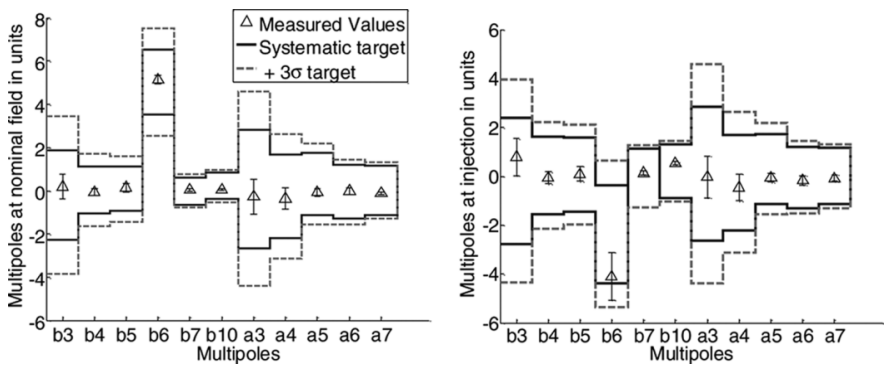

Fig. 11. Field quality of the MQM at nominal (left) and injection field (right). Same legend as in Fig. 8.

TABLE VII

MEASUREd DECAY FIELD ERRORS IN UNITS AND MT

\begin{tabular}{ccccc}
\hline \hline $\begin{array}{c}\text { Magnet } \\
\text { type }\end{array}$ & $\mathrm{b}_{\mathrm{n}}$ & $\begin{array}{c}\text { measured } \\
\mu \text { (units) }\end{array}$ & $\begin{array}{c}\text { measured } \\
\mu(\mathrm{mT})\end{array}$ & $\begin{array}{c}\text { measured } \\
\sigma \text { (units) }\end{array}$ \\
\hline MB & $\mathrm{b}_{1}$ & 1.31 & 0.07 & 1.20 \\
MB & $\mathrm{b}_{3}$ & 2 & 0.11 & 0.60 \\
MB & $\mathrm{b}_{5}$ & -0.33 & -0.02 & 0.12 \\
MQ & $\mathrm{b}_{2}$ & -3.74 & -0.28 & 2.40 \\
MQ & $\mathrm{b}_{6}$ & 0.54 & 0.04 & 0.34 \\
MQY & $\mathrm{b}_{2}$ & -6.00 & -0.27 & 2.00 \\
MQY & $\mathrm{b}_{6}$ & 0.45 & 0.02 & 0.12 \\
MQM & $\mathrm{b}_{2}$ & -4.50 & -0.25 & 1.20 \\
MQM & $\mathrm{b}_{6}$ & 0.50 & 0.03 & 0.24 \\
\hline \hline
\end{tabular}

insufficient compensation of the predicted persistent current effects $(-3.7 \pm 0.30$ unit) because the cross-section was initially designed for an injection current of $350 \mathrm{~A}$. The random components are basically inside the allowed bounds.

The field multipoles of $18 \mathrm{MQM}$ measured at $1.9 \mathrm{~K}$ is presented in Fig. 11. MQM multipoles are within the limits. The average $b_{6}$ is around 5 units at nominal field. At injection the shift due to persistent currents is large $(-9.2 \pm 0.30$ units $)$, leading to a value of $b_{6}$ at the limit of the window. The not allowed components are close to zero as expected from a good manufacturing procedure (no systematic asymmetries).

\section{Decay of the Persistent CurRents at InJeCtion Field}

A known effect in accelerator magnets operated at constant current like during particle injection is a field drift that affects mainly allowed multipoles with typical scales in the order of several minutes to several hours. This field decay is thought to originate from the interplay between cable current distribution and persistent currents in the filament [22]. The decay has been measured for a $1000 \mathrm{~s}$ injection plateau, after quench and a reference pre-cycle with a 30 min flat top at nominal current [23]. Table VII shows for the first allowed components the average 
and the spread of the decay in the case the MB, MQ, MQM and MQY magnets. The decay is quantified by taking the difference between the value at the beginning and at the end of injection plateau.

The drift with time is in particular strong for the main component of the quadrupoles with systematic errors of -6 units (MQY) and -4.5 units (MQM) and -3.74 units (MQ). A substantial scattering was also found among the magnets measured. The amplitude of the decay was different from magnet to magnet and did not depend on the cable combination type apart from the MB which shows inner layer dependence. The origin of this spread could not be correlated with the production parameters yet and no direct way to control the decay in magnets could be implemented.

\section{CONCLUSION}

All LHC magnets have been assigned in the machine, their installation and the commissioning of the first electrical circuits at cold are ongoing. An assessment of the magnetic measurement program can now be drawn. The global field quality picture expected for the machine is conform to beam optics requirements. The out of tolerance parameters (spread in $b_{3}$ for dipoles and in $b_{2}$ for quadrupoles) remain limited and cured with a dedicated installation scheme. The following critical points can be highlighted.

- The field error contributions caused by the geometry and by the difference in manufacturing can be corrected provided that a strict manufacturing control, an efficient steering of the production and an adapted sampling of direct magnetic measurements in operation conditions are performed.

- DC magnetization effect can be reasonably predicted for the MB and MQ multipoles using a model based on strand measurements despite the wide spectrum of cables used. For magnets operating at very low currents (MQM and MQY) the effect is large and difficult to predict leading to a large $b_{2}$-hysteresis and a non-optimized $b_{6}$. On the main component the measured effect is also significant. A part of this error may be generated by iron and collar magnetization rather than persistent currents.

- The impact of an out of tolerance magnetic permeability of the collars has been under-estimated. It weakens the strategy based on warm to cold correlation predictions and affects the behavior of the transfer function at low fields limiting our modeling capacity. This is of a particular importance for the MQY where the knowledge of $b_{2}$ is critical to avoid additional beta beating. The remedies would have been systematic measurements of the stainless sheet permeability or the measurement at cold of $100 \%$ of the transfer function.

- The major unknown left concerns the dynamic behavior reflected by the field decay at injection that remains uncontrolled. No correlations with the cable parameters could be found. A large effort was therefore dedicated to model the different behaviors and decay amplitudes as a function of the powering history of the machine [23].

\section{ACKNOWLEDGMENT}

The authors thank the teams in Industry, at CEA Saclay and at CERN involved in the construction and testing of the dipoles and quadrupoles. The authors thank the teams who built the test equipment, perform the cold tests operation and the analysis of the results.

\section{REFERENCES}

[1] LHC Design Report Vol.1, “The LHC Main Ring," CERN-2004-003 [Online]. Available: http://ab-div.web.cern.ch/ab-div/Publications/ LHC DesignReport.html

[2] P. Pugnat and A. Siemko, "Review of quench performance of LHC main superconducting magnets," IEEE Trans. Appl. Supercond., vol. 17, no. 2, pp. 1091-1096, 2007.

[3] E. Todesco et al., "Steering field quality in the main dipole magnets of the large Hadron collider," IEEE Trans. Appl. Supercond., vol. 14, pp. 177-180, 2004

[4] M. Di-Castro et al., Coupling current effects on LHC dipoles and quadrupoles this conference.

[5] P. Hagen et al., "Steering field quality in the production of the main quadrupoles of the large Hadron colllider," IEEE Trans. Appl. Supercond., vol. 14, no. 2, pp. 1051-1054, 2004.

[6] F. Savary et al., "History of the series production of the LHC main dipole magnets," in this conference.

[7] T. Tortschanoff et al., "The LHC main quadrupoles during series fabrication," IEEE Trans. Appl. Supercond., vol. 16, no. 2, pp. 281-284, 2006.

[8] G. Kirby et al., "The fabrication of the pre-series wide aperture superconducting quadrupoles for the LHC insertions," IEEE Trans. Appl. Supercond., vol. 14, pp. 207-210, 2004.

[9] D. Leroy, "Review of the R\&D and supply of the LHC superconducting cables," IEEE Trans. Appl. Supercond., vol. 16, no. 2, pp. 1152-1159, 2006.

[10] S. Fartoukh and O. Bruning, "Field quality specification for the LHC main dipole magnets," CERN, LHC project Report 501, 2001.

[11] E. Todesco, B. Bellesia, P. Hagen, and C. Vollinger, "Trends in field quality along the production of the LHC dipoles and differences among manufacturers," IEEE Trans. Appl. Supercond., vol. 16, no. 2, pp. 419-424, 2006.

[12] N. C. Lasheras, G. Kirby, R. Ostojic, and S. Russenschuck, “"'Effects of non-uniform permeability on the collars and yokes of the large aperture quadrupoles for the large Hadron collider,"," in this conference.

[13] A. Siemko et al., "Quench performance and field quality of the LHC preseries superconducting dipoles," IEEE Trans. Appl. Supercond., vol. 14, pp. $165-168,2004$

[14] W. Venturini-Delsolaro et al., "The test facility for the short prototype of the LHC superconducting magnets," in AIP Conf. Proc., 2002, vol. 613, pp. 106-113.

[15] J. Billan et al., "Twin rotating coils for cold magnetic measurements of $15 \mathrm{~m}$ long LHC dipoles," IEEE Trans. Appl. Supercond., vol. 10, no. 1, pp. 1422-1426, 2000.

[16] N. Smirnov et al., "Focusing strength measurements of the main quadrupoles-arc and special SSS for the LHC," IEEE Trans. Appl. Supercond., vol. 16, no. 2, pp. 261-264, 2006.

[17] B. Bellesia et al., "Trends in cable magnetization and persistent currents during the production of the main dipole of the Large Hadron Collider," IEEE Trans. Appl. Supercond., vol. 15, pp. 1213-1216, 2005.

[18] L. Bottura et al., "A review of persistent currents magnetization effects in superconducting accelerator magnets," Phys. Rev. B, submitted for publication.

[19] L. Bottura et al., "Magnet acceptance and allocation at the LHC magnet evaluation board," in Proceedings of PAC07, Albuquerque, New Mexico, USA, 2007, pp. 3739-3741.

[20] R. Wolf and S. Le Naour, The expected persistent current field errors in the LHC main dipole and quadrupole LHC Project Note 230, CERN, 2000.

[21] S. Le Naour et al., "Magnetization measurements on LHC superconducting strands," IEEE Trans. Appl. Supercond., vol. 9, no. 2, pp. 1763-1766, 1999.

[22] S. Amet et al., "Persistent and coupling current effects in the LHC superconducting dipoles," IEEE Trans. Appl. Supercond., vol. 13, pp. 1239-1242, 2003.

[23] N. Sammut et al., "The dependence of the field decay on the powering history of the LHC superconducting dipole magnets," in Proceedings of EPAC 2006, Edinburgh, Scotland, 2006, pp. 2619-2621. 